\title{
Avaliação dos níveis de selênio e glutationa peroxidase em pacientes críticos
}

\author{
Assessment of selenium and glutathione peroxidase levels in critically ill patients
}

\section{DOI: $10.37111 /$ braspenj.2020353005}

Neyla Edelwais Silva'

Cervantes Caporossi ${ }^{2}$

Alberto Bicudo Salomão ${ }^{3}$

Diana Borges Dock Nascimento ${ }^{4}$

Daniela Alencar Moreira ${ }^{5}$

\section{Unitermos:}

Selênio. Glutationa Peroxidase. Antioxidantes. Inflamação. Cuidados críticos.

\section{Keywords:}

Selenium. Glutathione Peroxidase. Antioxidants. Inflammation. Critical Care.

\section{Endereço para correspondência:}

Neyla Silva

Hospital Universitário Júlio Muller - Unidade de Nutrição Clínica

Rua Luiz Philipe Pereira Leite, s/n - Alvorada - Cuiabá, MT, Brasil - CEP: 78048-902

E-mail: neylanutri@gmail.com

\section{Submissão}

2 de março de 2020

Aceito para publicação

2 de setembro de 2020

\begin{abstract}
RESUMO
Introdução: A capacidade do selênio na redução de radicais livres, associada à sua atuação como cofator essencial para a glutationa peroxidase, confere um potencial papel para pacientes em unidade de terapia intensiva. $O$ objetivo deste trabalho foi avaliar os níveis plasmáticos de selênio e glutationa peroxidase à admissão e pelo período de 7 dias de evolução em pacientes hospitalizados. Método: Estudo observacional com pacientes adultos $(n=22)$ internados em unidade de terapia intensiva. Foram realizadas três coletas de sangue, nos dias 1, 3 e 7, para avaliar o selênio, e duas para glutationa peroxidase, nos dias 1 e 7 . Não houve nenhum tipo de intervenção. Resultados: Os níveis de selênio à admissão foram abaixo dos valores de referência em metade dos pacientes. Ao estratificar os pacientes $(n=22)$ conforme risco de complicações infecciosas e inflamatórias (relação proteína $C$ reativa/albumina), os pacientes classificados em alto risco possuíam dosagem de selênio à admissão inferior aos de risco moderado $(p=0,032)$. Dentre os pacientes com seguimento completo (realizadas todas as dosagens), $66,7 \%$ eram de alto risco e entre eles $75 \%$ apresentaram selênio abaixo dos valores de referência e inferior ao grupo de risco moderado $(p=0,014)$. As dosagens da glutationa peroxidase estavam dentro da normalidade em todos pacientes, independente da classificação. Conclusão: Aproximadamente $50 \%$ dos pacientes críticos foram admitidos na unidade de terapia intensiva com selênio abaixo dos valores de referência. À admissão e na evolução até o sétimo dia, os pacientes classificados de alto risco apresentaram dosagem de selênio abaixo do valor de referência e inferior ao daqueles com risco moderado.
\end{abstract}

\section{ABSTRACT}

Introduction: The ability of selenium to reduce free radicals, associated with its performance as an essential cofactor for glutathione peroxidase, confers a potential role for patients in the intensive care unit. The aim of this study was to evaluate the plasma levels of selenium and glutathione peroxidase at admission and for the period of 7 days of evolution in hospitalized patients. Methods: Observational study with adult patients $(n=22)$ admitted to the intensive care unit. Three blood samples were taken, on days 1, 3 and 7, to assess selenium, and two for glutathione peroxidase, on days 1 and 7. There was no type of intervention. Results: Selenium levels at admission were below the reference values in half of the patients. When stratifying patients $(n=22)$ according to the risk of infectious and inflammatory complications (C-reactive protein / albumin ratio), patients classified as high risk had selenium dosage at admission below those of moderate risk ( $p$ $=0.032$ ). Among patients with complete follow-up (all dosages were performed), $66.7 \%$ were at high risk and among them $75 \%$ had selenium below the reference values and below the moderate risk group ( $p=0.014)$. Glutathione peroxidase dosages were normal in all patients, regardless of classification. Conclusion: Approximately $50 \%$ of critically ill patients were admitted to the intensive care unit with selenium below the reference values. On admission and progression to the seventh day, patients classified as high risk had selenium dosage below the reference value and below that of patients at moderate risk.

1 Mestre, Especialista em Nutrição Clínica, Parenteral e Enteral, nutricionista da equipe multidisciplinar de terapia nutricional do Hospital Universitário Júlio Muller/ Universidade Federal de Mato Grosso, Programa de Mestrado Profissional, Cuiabá, MT, Brasil.

2. Doutor, Universidade Federal de Mato Grosso, Faculdade de Medicina, Programa de Pós-graduação em Ciências Aplicadas à Gestão Hospitalar (PPGCAAH), Hospital Santa Rosa, Cuiabá, MT, Brasil.

3. Doutor, Hospital Universitário Júlio Muller/ Universidade Federal de Mato Grosso, Faculdade de Medicina. PPGCAAH, Cuiabá, MT, Brasil.

4. Doutora, nutricionista, Hospital Universitário Júlio Muller/ Universidade Federal de Mato Grosso, Departamento de Alimentos e Nutrição, Faculdade de Nutrição, Cuiabá, MT, Brasil.

5. Mestre, Farmacêutica da equipe multidisciplinar de terapia nutricional do Hospital Universitário Júlio Muller/ Universidade Federal de Mato Grosso, Programa de Mestrado Profissional, Cuiabá, MT, Brasil. 


\section{INTRODUÇÃO}

O selênio exerce papel significativo na regulação da atividade imunológica e antioxidante ${ }^{1-3}$. Desempenha função nos sistemas biológicos por meio das selenoproteínas ${ }^{1,4}$. Seu nível sanguíneo considerado padrão apresenta um amplo intervalo na dosagem normal, que é dependente de fatores como o nível social da população estudada, da sua dieta e, um fator muito referido na literatura é a área geográfica, pois seu teor no alimento varia de acordo com a composição do solo $0^{1,3}$. A deficiência de selênio pode estar associada a algumas doenças, como asma, distúrbios da circulação², cardiomiopatias e osteoartropatias. Após a descoberta dessas doenças, na década de 1960, definiu-se o selênio como oligoelemento essencial para os seres humanos'. Em contrapartida, seu excesso causa toxicidade e sintomas de intoxicação alimentar, podendo ocasionar distúrbios neurológicos ${ }^{1,2}$.

Em condições fisiológicas, a deficiência de selênio pode ser assintomática. Entretanto, quando ocorre exposição do paciente a uma situação de agravo crítico à sua condição clínica, a proteção antioxidante pode estar associada a um maior consumo e, em caso de déficit, pode determinar uma resposta clínica deficiente e, assim, a uma evolução desfavorável'.

A capacidade antioxidante e anti-inflamatória confere ao selênio um papel potencialmente importante para pacientes em unidade de terapia intensiva (UTI), principalmente nos pacientes com a síndrome da resposta inflamatória sistêmica (SIRS) e/ou síndrome de disfunção de múltiplos órgãos (MODS)5. Paralelamente, é um cofator essencial para o funcionamento da glutationa peroxidase $(G P x)^{4,6}$. Ela é uma das principais enzimas que incluem estruturalmente 0 selênio (selenoproteínas) e possui função na manutenção da integridade da membrana celular, atividade dos neutrófilos, redução do estresse e danos oxidativos e controle da cascata inflamatória ${ }^{2,3,7}$. Desta forma, a glutationa peroxidase parece ser um biomarcador promissor para avaliar o estresse oxidativo em pacientes sépticos ${ }^{4,5}$. Em doenças com componente inflamatório, a concentração de selênio diminui e a biossíntese de selenoproteínas é desregulada. Portanto, a interpretação clínica dos níveis séricos de selênio guarda relação com o grau de inflamação, como observado, por exemplo, com os níveis de proteínas de fase aguda, especialmente a proteína $C$ reativa $(P C R)$ e albumina ${ }^{1,7,8}$. Raciocínio similar pode ser feito no que tange aos níveis séricos da glutationa peroxidase.

Isto nos permite inferir que os níveis plasmáticos de selênio e glutationa peroxidase em pacientes críticos, desde o momento de sua admissão e durante o período de evolução na UTI, constituem um marcador importante a ser investigado. O objetivo deste estudo foi avaliar os níveis plasmáticos de selênio e glutationa peroxidase, à admissão e pelo período de 7 dias de evolução, em pacientes internados em UTI.

\section{MÉTODO}

Estudo observacional, por tempo determinado, com intenção de análise por protocolo envolvendo pacientes internados na UTI de um hospital particular em Cuiabá MT (Brasil). Foi aprovado pelo Comitê de Ética em Pesquisa do Hospital Universitário Júlio Muller (número 1.844.012 e CAAE 61313716.4.0000.5541). Os pacientes foram incluídos por consentimento próprio ou de seu responsável, assinando o termo de consentimento livre e esclarecido.

Os critérios de inclusão foram: pacientes de ambos os sexos, internados em UTI geral, com idade entre 18 e 65 anos, sem reposição oral, enteral ou parenteral de selênio. Os critérios de exclusão foram: pacientes oncológicos, gestantes, com história prévia de doença da tireoide, submetidos a um programa de diálise em qualquer momento da internação na UTI e internados em Unidade Coronariana.

Após acolhimento na UTI, os pacientes foram submetidos a coleta de sangue: a) selênio - três amostras, sendo a primeira nas primeiras 24 horas de internação (dia 1), a segunda, no terceiro dia (dia 3) e a última, no sétimo dia (dia 7); b) glutationa peroxidase - duas amostras, nos dias 1 e 7 .

Os pacientes foram submetidos apenas a coleta de sangue, realizada no mesmo momento dos exames de admissão rotineiros da Unidade, otimizando tempo e minimizando possíveis riscos. As análises foram feitas no mesmo laboratório da coleta e o método padronizado para o selênio a partir do sangue total, por meio de espectrofotometria de absorção atômica por forno de grafite, método in house. Para a glutationa peroxidase utilizou-se a espectrofotometria.

O valor de normalidade padrão para selênio é entre 46 $\mu \mathrm{g} / \mathrm{L} \mathrm{e} 143 \mu \mathrm{g} / \mathrm{L}$. Baseado nestes valores, os pacientes foram classificados em: a) $\leq 46 \mu \mathrm{g} / \mathrm{L}$ : níveis baixos; b) entre 46 $\mu \mathrm{g} / \mathrm{L}$ e $143 \mu \mathrm{g} / \mathrm{L}$ : dentro dos valores de referência; c) $\geq 143$ $\mu \mathrm{g} / \mathrm{L}$ : níveis elevados. Os valores de normalidade para glutationa peroxidase são entre $4171 \mathrm{U} / \mathrm{L}$ e $10881 \mathrm{U} / \mathrm{L}$. Assim, os pacientes foram classificados em: a) $\leq 4171 \mathrm{U} / \mathrm{L}$ : níveis baixos; b) entre $4171 \mathrm{U} / \mathrm{L}$ e $10881 \mathrm{U} / \mathrm{L}$ : dentro dos valores de referência; c) $\geq 10881 \mathrm{U} / \mathrm{L}$ : níveis elevados.

Além do selênio e da glutationa peroxidase, foram avaliadas PCR e albumina. Com estes resultados, foi determinado um parâmetro do estado inflamatório, usando a escala do Escore Prognóstico de Glasgow (GPS), o qual utiliza a relação PCR/albumina, que constitui uma alternativa para a simplificação da fórmula original do Índice Prognóstico Inflamatório e Nutricional $1^{9,10}$.

Assim, os pacientes foram classificados, à admissão na Unidade, conforme o grau de risco de complicações segundo a relação $P C R / a l b u m i n a$, a saber: sem risco $(\leq 0,4)$, baixo risco $\left(0,4\right.$ a 1,2), médio risco $(1,2$ a 2,0$)$ e alto risco $(\geq 2,0)^{11}$. 
Neste estudo, optou-se em estratificar os pacientes em dois grandes grupos: alto risco (relação PCR/albumina $\geq 2,0$ ) e risco moderado (relação $P C R /$ albumina $\leq 2,0$ ). A PCR e a albumina são dosadas na rotina de exames na UTI e seus valores de referência são $0 \mathrm{mg} / \mathrm{dL}$ a $5 \mathrm{mg} / \mathrm{dL}$ e $3,5 \mathrm{~g} / \mathrm{dL}$ a $5,2 \mathrm{~g} / \mathrm{dL}$, respectivamente. Os pacientes foram avaliados em relação ao seu estado nutricional pela Avaliação Subjetiva Global (ASG) e foram classificados em: A- bem nutrido, B- moderadamente ou suspeita de estar desnutrido e Cdesnutrido grave ${ }^{12}$. Não houve estratificação de acordo com a terapia nutricional ofertada.

Para as análises estatísticas, todas as variáveis apresentaram distribuição normal após a aplicação do teste de Kolmogorov-Smirnov, justificando-se, assim, a utilização de métodos estatísticos paramétricos. As dosagens foram comparadas por meio do teste t de Student, segundo o grau de risco. Para comparação entre o grupo de alto risco e moderado foram empregados o teste de ANOVA e o coeficiente de contingência. $\bigcirc$ nível de significância adotado foi de $5 \%(p<0,05)$. Utilizou-se os programas Excel e SPSS 13.0 for Windows.

\section{RESULTADOS}

No período de agosto de 2017 a março de 2018, foram observados 22 pacientes, sendo $12(54,5 \%)$ homens e 10 $(45,5 \%)$ mulheres, com idade média de 42 anos. $O$ motivo da admissão na UTI foi: insuficiência respiratória ( $n=7 ; 32 \%)$, doença neurológica $(n=9 ; 41 \%)$ e pós-operatório $(n=6$; $27 \%)$. A mortalidade foi de $4,5 \%(n=1)$.

Os pacientes foram classificados de acordo com seu estado nutricional pela $\mathrm{ASG}^{12} \mathrm{em:} \mathrm{A}(\mathrm{n}=3 ; 13,6 \%), \mathrm{B}(\mathrm{n}=17$; $77,3 \%)$ e $C(n=2 ; 9,1 \%)$, conforme demonstrado na Tabela 1. A ASG, à admissão na UTI, não demonstrou correlação com
Tabela 1 - Relação dos pacientes na fase 1 ( $n=22)$, conforme estado nutricional (Avaliação Subjetiva Global) e dosagem de selênio à admissão na UTI.

\begin{tabular}{lccc}
\hline \multicolumn{4}{c}{ Selênio } \\
\hline ASG & Abaixo da & Dentro da & Total \\
& normalidade & normalidade & \\
\hline A & 2 pacientes & 1 paciente & 3 pacientes \\
B & 8 pacientes & 9 pacientes & 17 pacientes \\
C & 1 paciente & 1 paciente & 2 pacientes \\
Total & 11 pacientes & 11 pacientes & 22 pacientes \\
\hline
\end{tabular}

ASG = Avaliação Subjetiva Global; $\mathrm{A}$ = bem nutrido; $\mathrm{B}$ = moderadamente ou suspeita de estar desnutrido; $\mathrm{C}=$ desnutrido grave.

o nível de selênio durante o período do estudo, indicando uma associação fraca (coeficiente de contingência $=0,015$ ).

Todos os 22 pacientes iniciaram terapia nutricional precoce nas primeiras 48 horas após a entrada na UTI, e ninguém permaneceu em dieta zero. A dieta foi administrada por via oral para $82 \%(n=18)$ dos pacientes, e destes, em $11 \%(n=2)$ houve associação de suplemento oral hipercalórico. Os demais estavam em terapia de nutrição enteral $(n=6 ; 27 \%)$, associada ou não à dieta oral e não houve necessidade do uso de terapia de nutrição parenteral. Quanto à assistência respiratória, 23\% $(n=5)$ dos pacientes estavam em ventilação mecânica.

A intenção do estudo foi uma análise por protocolo. $\mathrm{Na}$ Figura 1, podemos observar que 22 pacientes iniciaram o estudo (fase 1), porém apenas em 12 participantes o seguimento foi completo (fase 2), ou seja, foram submetidos às três coletas de selênio e às duas de glutationa peroxidase no período de sete dias consecutivos de internação na UTI. Os pacientes que não cumpriram as etapas foram retirados da pesquisa devido à alta da UTI para enfermaria $(n=9)$ ou óbito $(n=1)$.

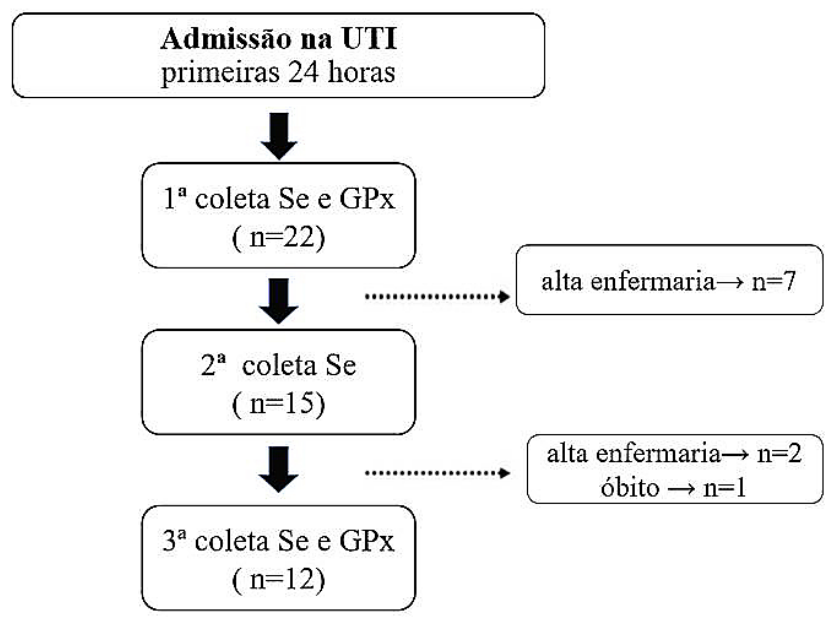

Figura 1 - Fluxograma do estudo. Se = selênio, GPx = glutationa peroxidase. 
$\mathrm{Na}$ Tabela 2, estão representados os valores de selênio e glutationa peroxidase nos três momentos do estudo; os dados estão expressos em média e desvio padrão com o respectivo número de pacientes, conforme o dia da coleta. Observase que, no momento da internação na UTI, a concentração média de selênio $(45,4 \pm 16,0 \mu \mathrm{g} / \mathrm{L})$ no plasma dos 22 pacientes que iniciaram o estudo estava abaixo do valor de referência (46 a $143 \mu \mathrm{g} / \mathrm{L})$. Em relação à glutationa peroxidase, os valores $(6131,6 \pm 1893,3 \mathrm{U} / \mathrm{L})$ estavam dentro da normalidade (4171 a $10881 \mathrm{U} / \mathrm{L})$. $O$ valor médio da dosagem do selênio, assim como da GPx, não sofreu alteração significativa nas dosagens posteriores, embora deva-se considerar que foram realizadas com amostras de número diferente de pacientes em cada momento.

Tabela 2 - Dosagem sanguínea de selênio e glutationa peroxidase (média \pm DP), conforme os dias de coleta $-1^{\circ} \mathrm{dia}, 3^{\circ}$ dia e $7^{\circ}$ dia.

\begin{tabular}{|c|c|c|c|}
\hline & $\begin{array}{l}1^{\circ} \text { dia } \\
(n=22)\end{array}$ & $\begin{array}{l}3^{\circ} \text { dia } \\
(n=15)\end{array}$ & $\begin{array}{l}7^{0} \text { dia } \\
(n=12)\end{array}$ \\
\hline $\begin{array}{l}\text { Selênio } \\
(\mu \mathrm{g} / \mathrm{L})\end{array}$ & $\begin{array}{c}45,4^{*} \\
( \pm 16,0)^{\star}\end{array}$ & $\begin{array}{c}49,1 \\
( \pm 13,0)\end{array}$ & $\begin{array}{c}52,8 \\
( \pm 21,5)\end{array}$ \\
\hline $\begin{array}{l}\text { Glutationa } \\
\text { peroxidase } \\
\text { (U/L) }\end{array}$ & $\begin{array}{c}6131,6^{\star \star} \\
( \pm 1893,3)\end{array}$ & - & $\begin{array}{c}6189,3 \\
( \pm 1802,4)\end{array}$ \\
\hline
\end{tabular}

${ }^{*} p>0,05$ versus dosagem do $3^{\circ}$ dia e $7^{\circ}$ dia; ** $p>0,05$ versus dosagem $7^{\circ}$ dia.
Os pacientes $(n=22)$ foram classificados categoricamente em alto risco e risco moderado. Para este fim, utilizou-se uma simplificação do Índice Prognóstico Inflamatório Nutricional (relação PCR/albumina), para estimar o risco de complicação na UTI ${ }^{11,13}$. Este indicador de gravidade é estabelecido no momento da internação e norteia a classificação de gravidade até a alta, motivo pelo qual é destacado apenas no acolhimento. Dessa forma, os valores médios de selênio e glutationa peroxidase estão demonstrados na Tabela 3.

Observa-se que, ao dividir os pacientes nestes grupos, os de alto risco possuíam dosagem de selênio à admissão inferior aos de risco moderado $(p=0,032)$. Não foi realizada análise estatística dos outros dias em virtude do número diferente de pacientes em cada dia. Em relação à glutationa peroxidase, os valores à admissão estavam dentro da faixa de normalidade e são estatisticamente semelhantes entre os dois grupos $(p=0,364)$.

Conforme o grupo de risco, na Tabela 4 estão relacionados separadamente os pacientes da fase 1, a dosagem de selênio na data da sua admissão e o percentual de doentes com o nível de selênio consoante ao índice de normalidade. Pode-se observar que foram alocados exatamente em igual número $(n=11)$ entre classificados de alto risco e de risco moderado. A dosagem do selênio ( $\left.1^{\circ} \mathrm{dia}\right)$ no grupo de alto risco apresentava valor médio inferior ao dos pacientes classificados em risco moderado $(p=0,032)$.

Tabela 3 - Dosagem de selênio e glutationa peroxidase nos momentos do estudo, conforme classificação de risco para complicações infecciosas e inflamatórias (relação PCR/albumina).

\begin{tabular}{lccccc}
\hline $\begin{array}{l}\text { Classificação de } \\
\text { risco }\end{array}$ & \multicolumn{3}{c}{ Selênio $(\boldsymbol{\mu g} / \mathbf{L})$} & \multicolumn{2}{c}{ GPx (U/L) } \\
\hline & $\begin{array}{c}\mathbf{1}^{\circ} \text { dia } \\
(\mathbf{n}=22)\end{array}$ & $\begin{array}{c}3^{\circ} \text { dia } \\
(\mathbf{n}=15)\end{array}$ & $\begin{array}{c}7^{\circ} \text { dia } \\
(\mathbf{n}=12)\end{array}$ & $\begin{array}{c}1^{\circ} \text { dia } \\
(\mathbf{n}=\mathbf{2 2})\end{array}$ & $\begin{array}{c}7^{\circ} \text { dia } \\
(\mathbf{n}=12)\end{array}$ \\
\hline Risco moderado & $52,6( \pm 17,0)$ & $50,7( \pm 17,6)$ & $55,2( \pm 13,53)$ & $6364( \pm 1891,1)$ & $6093,5( \pm 920,5)$ \\
Alto risco & $38,2^{*}( \pm 11,6)$ & $47,4( \pm 11,3)$ & $54,9( \pm 20,6)$ & $5662^{* \star}( \pm 1825,8)$ & $6237,2( \pm 2175,7)$ \\
\hline
\end{tabular}

GPx = Glutationa peroxidase; $\mathrm{n}=$ número de pacientes

${ }^{*} p=0,032$ versus risco moderado à admissão $(n=22) ;{ }^{* *} p=0,364$ versus risco moderado à admissão $(n=22)$.

Tabela 4 - Dosagem de selênio à admissão na UTI (n=22), segundo a classificação do risco de complicações infecciosas e inflamatórias (relação PCR/ albumina).

\begin{tabular}{|c|c|c|c|c|c|}
\hline \multirow{2}{*}{$\begin{array}{l}\text { Classificação de } \\
\text { risco }\end{array}$} & \multirow{2}{*}{$\begin{array}{c}\text { Média } \\
\text { Selênio } \\
(\mu \mathrm{g} / \mathrm{L})\end{array}$} & \multicolumn{2}{|c|}{ Níveis Selênio } & \multirow[b]{2}{*}{$\underset{(n=22)}{n}$} & \multirow[b]{2}{*}{$\%$} \\
\hline & & $\begin{array}{l}\text { Abaixo da normalidade } \\
(\mathrm{n} / \%)\end{array}$ & $\begin{array}{l}\text { Dentro da normalidade } \\
\qquad(n / \%)\end{array}$ & & \\
\hline Risco moderado & $52,6( \pm 17,0)$ & $4(36,4 \%)$ & $7(63,6 \%)$ & 11 & 50 \\
\hline Alto risco & $38,2( \pm 11,6)^{\star}$ & 7 (63,6\%) & $4(36,4 \%)$ & 11 & 50 \\
\hline
\end{tabular}

${ }^{*} p=0,032$ versus risco moderado à admissão $(n=22)$. 
Complementa a análise dos dados, o detalhe que o percentual de pacientes classificados de alto risco que ficam alocados entre os com selênio abaixo da normalidade $(63,6 \%)$ ser maior numericamente que os dentro da normalidade $(36,4 \%)$. Optou-se por não realizar tal apresentação em relação à glutationa peroxidase em virtude de seus valores estarem dentro da normalidade e serem semelhantes entre os dois grupos.

Analisou-se, também, a amostra que completou todo o protocolo estabelecido (fase 2) em relação à dosagem de selênio e glutationa peroxidase $(n=12)$ e estratificada pelo Índice Prognóstico Inflamatório Nutricional (Tabela 5). Observa-se, nesta tabela, que a dosagem do selênio no grupo de alto risco $(35,2 \pm 11,1 \mu \mathrm{g} / \mathrm{L})$ estava abaixo da normalidade e inferior estatisticamente em relação ao grupo de risco moderado $(p=0,014)$. As análises estatísticas realizadas subsequentes, tanto para o selênio como para a GPx, demonstraram valores semelhantes no estudo intragrupo, bem como no intergrupo.

Conforme observa-se na Tabela 6, a média do selênio no grupo de alto risco $(35,2 \pm 11,1 \mu \mathrm{g} / \mathrm{L})$ estava abaixo da normalidade e inferior estatisticamente em relação ao grupo de risco moderado $(p=0,014)$. Novamente, o percentual de pacientes classificados de alto risco, os quais ficam alocados entre os com selênio abaixo da normalidade $(75 \%)$, é numericamente superior que os dentro da normalidade (25\%). Em relação à dosagem da glutationa peroxidase (Tabela 7), os resultados nos pacientes da fase 2 foram semelhantes, independente do grupo de risco $(p=0,262)$.

Tabela 5 - Dosagem de selênio e glutationa peroxidase nos momentos do estudo, segundo a classificação de risco de complicações infecciosas e inflamatórias (relação PCR/albumina) em pacientes na fase 2 ( $n=12)$.

\begin{tabular}{|c|c|c|c|c|c|}
\hline \multirow[t]{2}{*}{ Classificação de risco } & \multicolumn{3}{|c|}{ Selênio } & \multicolumn{2}{|c|}{ GPx } \\
\hline & $\begin{array}{l}1^{0} \mathrm{dia} \\
(\mathrm{n}=22)\end{array}$ & $\begin{array}{l}3^{\circ} \text { dia } \\
(n=15)\end{array}$ & $\begin{array}{l}7^{\circ} \mathrm{dia} \\
(\mathrm{n}=12)\end{array}$ & $\begin{array}{l}1^{\circ} \mathrm{dia} \\
(\mathrm{n}=22)\end{array}$ & $\begin{array}{l}7^{\circ} \text { dia } \\
(n=12)\end{array}$ \\
\hline Risco moderado & $50,8( \pm 11,7)$ & $48,5( \pm 20,3)$ & $55,2( \pm 13,5)$ & $6891,2( \pm 2122,8)$ & $6093,5( \pm 920,5)$ \\
\hline Alto risco & $35,2^{*}( \pm 11,1)$ & $47,4( \pm 12,1)$ & $54,9( \pm 20,6)$ & $6032,1( \pm 2128,7)$ & $6237,2( \pm 2175,7)$ \\
\hline
\end{tabular}

Selênio $(\mu \mathrm{g} / \mathrm{L})$, glutationa peroxidase - GPx (U/L).

${ }^{*} \mathrm{p}=0,014$ versus risco moderado no $1^{\circ} \mathrm{dia}$.

Tabela 6 - Dosagem de selênio à admissão na UTI em pacientes da fase 2 ( $n=12)$, segundo a classificação de risco de complicações infecciosas e inflamatórias (relação PCR/albumina).

\begin{tabular}{lccccc}
\hline Classificação de & Selênio & \multicolumn{2}{c}{ Níveis Selênio } & & \\
\cline { 3 - 5 } & $(\boldsymbol{\mu g} / \mathbf{L})$ & $\begin{array}{c}\text { Abaixo da normalidade } \\
(\mathbf{n} / \%)\end{array}$ & $\begin{array}{c}\text { Dentro da normalidade } \\
(\mathbf{n} / \%)\end{array}$ & $\begin{array}{c}\mathbf{n} \\
(\mathbf{n}=22)\end{array}$ & $\%$ \\
\hline Risco moderado & $50,8( \pm 11,7)$ & $1(25 \%)$ & $3(75 \%)$ & 4 & 33,3 \\
Alto risco & $35,2( \pm 11,1)^{\star}$ & $6(75 \%)$ & $2(25 \%)$ & 8 & 66,7 \\
\hline
\end{tabular}

${ }^{*} p=0,014$ versus risco moderado.

Tabela 7 - Dosagem de selênio à admissão na UTI em pacientes da fase 2 ( $n=12)$, segundo a classificação de risco de complicações infecciosas e inflamatórias (relação PCR/albumina).

\begin{tabular}{|c|c|c|c|c|c|}
\hline \multirow{2}{*}{$\begin{array}{l}\text { Classificação de } \\
\text { risco }\end{array}$} & \multirow{2}{*}{$\begin{array}{l}\text { GPx } \\
\text { (U/L) }\end{array}$} & \multicolumn{2}{|c|}{ Níveis GPx } & \multirow[b]{2}{*}{$\begin{array}{c}n \\
(n=22)\end{array}$} & \multirow[b]{2}{*}{$\%$} \\
\hline & & $\begin{array}{l}\text { Abaixo da normalidade } \\
\qquad(\mathrm{n} / \%)\end{array}$ & $\begin{array}{l}\text { Dentro da normalidade } \\
\qquad(\mathrm{n} / \%)\end{array}$ & & \\
\hline Risco moderado & $6891,2( \pm 2122,8)$ & - & $4(100 \%)$ & 4 & 33,3 \\
\hline Alto risco & $6032,1( \pm 2128,7)^{\star}$ & $2(25 \%)$ & $6(75 \%)$ & 8 & 66,7 \\
\hline
\end{tabular}

* $p=0,262$ versus risco moderado. 


\section{DISCUSSÃO}

A dosagem do selênio estava abaixo do nível da normalidade no acolhimento na UTI em $50 \%$ dos pacientes. No grupo de participantes que completaram o protocolo de 7 dias ( $n=12)$, e após estratificação em maior e menor risco avaliado pela resposta inflamatória baseada na relação PCR/albumina, a camada de representantes de alto risco apresentou dosagem de selênio inicial significativamente menor que a de risco moderado.

A disponibilidade de oligoelementos é modificada durante a doença crítica por várias razões, tais como aumento do catabolismo e excreção urinária. A SIRS está associada à redistribuição de vitaminas e oligoelementos do compartimento circulante para os tecidos envolvidos na síntese de proteínas e proliferação de células imunes ${ }^{5}$. Pressupõe-se que, quanto mais grave o trauma, a SIRS ou a sepse, maior deve ser a depleção de antioxidantes ${ }^{14}$. A ASG é recomendada como a melhor ferramenta de avaliação nutricional na UTI15,16. A revisão sistemática da literatura sustenta a alegação de que a desnutrição está independentemente associada a piores desfechos clínicos na UTI, pois atinge o indivíduo no seu pleno, inclusive em componentes ainda pouco valorizados, como o selênio ${ }^{15}$.

Neste estudo, 9,1\% dos pacientes foram classificados como desnutridos graves, ASG C. Não foi possível comprovar uma relação direta entre estado nutricional avaliado pela ASG e os níveis de selênio. Todavia, é importante ressaltar que o paciente classificado como desnutrido grave (ASG C) foi a óbito durante o período do estudo e não houve mortalidade entre os pacientes bem nutridos (ASG A).

No presente estudo, à admissão na UTI (dia 1), metade dos pacientes apresentou nível de selênio plasmático abaixo dos valores de referência. Isto pode ser um reflexo da característica da população regional ou uma associação com - comprometimento fisiopatológico potencializado pela gravidade do paciente. Sustenta este raciocínio o fato que, quando foram estratificados em moderado ou alto risco, avaliado pela resposta inflamatória, os pacientes classificados com maior escore para inflamação apresentaram dosagem de selênio inicial significativamente menor que os pacientes com risco moderado. Em relação à glutationa peroxidase, não foi encontrada dosagem abaixo da referência ou mesmo diferença estatisticamente significante nas duas coletas, nos dias 1 e 7 ( $p=0,364)$.

Corroborando com este estudo, alguns autores demonstraram que a concentração plasmática de selênio não diminuiu durante a permanência na UTI em pacientes sem SIRS. Outro estudo identificou aumento nas concentrações de selênio plasmático em pacientes sem SIRS, ao longo de 1 a 3 dias de acompanhamento ${ }^{14}$. Essas diferenças podem ser explicadas por três mecanismos: inexistência ou reduzido grau de estresse oxidativo, ausência de redistribuição de selênio entre os compartimentos ou pouca ou nenhuma hemodiluição ${ }^{5}$.

Nos pacientes da fase 2, o nível de selênio no grupo de alto risco tem valores abaixo da normalidade e inferiores ao grupo de risco moderado. Porém, não se identificou uma queda nos níveis nos dias subsequentes do estudo, independente da gravidade do grupo. Apesar de considerados pacientes críticos, em UTI, o grau de inflamação dos pacientes não era intenso, fato que apenas um paciente foi a óbito em todo o tempo da coleta de dados. Em relação à glutationa peroxidase, não houve diferença entre os grupos nos dias estudados.

Durante o período do estudo, observou-se que, da admissão à alta da UTI, na maioria das vezes, o selênio nem é citado. Após uma revisão nas prescrições, nenhuma constava selênio, seja dosagem laboratorial ou reposição/ suplementação.

Algumas limitações deste estudo incluíram a heterogeneidade da amostra e o reduzido número de pacientes que completaram o método desenhado. A saída do estudo por óbito foi pequena, porém devido à dificuldade do acompanhamento fora da unidade fechada, os pacientes foram excluídos das dosagens quando nas enfermarias. Não temos dados sobre a ingestão alimentar prévia do paciente, nem se receberam qualquer suplementação de selênio antes da admissão na UTI.

A revisão dos dados da literatura revela que a ingestão de selênio pode variar de acordo com a região geográfica e hábitos alimentares, além de uma variabilidade considerável nos valores de referência. Estudos realizados no Brasil apontam reflexos diretos na ingestão alimentar de selênio, de acordo com o conteúdo mineral nos solos. Refeições analisadas revelaram que Mato Grosso apresentou os menores índices de selênio do Brasil (19 $\mu \mathrm{g} / \mathrm{dia})$, sugerindo divergências dependendo da região e também do nível socioeconômico da população estudada ${ }^{17}$. Estes fatores podem ter influenciado os valores encontrados de selênio ao longo deste estudo.

Dessa forma, a janela de risco-benefício para o consumo de selênio é muito estreita, levando a resultados confusos de estudos epidemiológicos e de intervenção e destacando a importância de variações interindividuais na resposta ao consumo de selênio, resultando em grandes diferenças de ingestão diária entre as populações. Confirmando esses achados, um estudo norte-americano não revelou a deficiência de selênio observada consistentemente em estudos europeus e sul-americanos em pessoas criticamente doentes e saudáveis. Essas diferenças podem refletir a considerável depleção de selênio no solo observada em partes da Europa, mas não em toda a América do Norte ${ }^{18}$. Embora tenha 
sido esperada uma associação positiva entre níveis séricos de selênio com atividade da glutationa peroxidase, alguns estudos encontraram resultados controversos. A resposta das variações genéticas sobre os nutrientes e sua interação na doença também pode ser uma razão pela qual não foram encontradas associações entre a atividade de selênio e glutationa peroxidase. A ingestão de selênio na dieta pode diferir entre indivíduos e pode ser devido a variantes genéticas nas selenoproteínas. Por sua vez, isso pode influenciar a forma como o organismo metaboliza e utiliza selênio ${ }^{6}$.

Portanto, é difícil comparar os níveis plasmáticos entre os diferentes estudos. Em pacientes criticamente enfermos, postula-se que seu nível plasmático pode ser afetado pela resposta inflamatória ${ }^{19}$. No entanto, no estudo REDOXS, pacientes com sepse apresentaram a mesma quantidade de selênio que o grupo controle ${ }^{18,19}$.

Recentemente, as diretrizes clínicas da American Society for Parenteral and Enteral Nutrition (ASPEN) e Society of Critical Care Medicine (SCCM) ${ }^{20}$ ainda não concluíram uma recomendação final sobre a terapia com selênio em pacientes adultos sépticos ${ }^{21}$. Já as diretrizes canadenses recomendam que o selênio, sozinho ou em combinação com outros antioxidantes, seja considerado em pacientes criticamente doentes ${ }^{22,23}$.

No estudo multicêntrico REDOXS, as altas doses de suplementação não foram associadas a resultados positivos $^{18}$. Outros ensaios clínicos randomizados encontraram resultados positivos em desfechos clinicamente relevantes para pacientes graves, incluindo reduções nas complicações infecciosas e taxas de mortalidade ${ }^{21}$. Como, por exemplo, o estudo escocês SIGNET concluiu que pode haver benefício em suplementar a nutrição parenteral com $500 \mu \mathrm{g}$ de selênio diariamente por pelo menos cinco dias durante a doença crítica, em termos de risco de nova infecção ${ }^{24}$. E um outro estudo, a suplementação de selênio resultou em aumento na concentração de glutationa peroxidase ${ }^{3}$. A compreensão sobre os oligoelementos é uma das questões mais desconhecidas em pacientes graves, apesar do seu envolvimento na maioria das defesas imunológicas. Isto é devido à falta de conhecimento e dificuldades na mensuração ${ }^{25}$. Detectando as características do selênio em pacientes internados em um hospital particular de Cuiabá, a partir de uma amostra, espera-se abrir uma janela de oportunidades para a análise dos micronutrientes com função antioxidante, a qual não é realizada de rotina na prática médica, principalmente em unidades críticas de tratamento, instigando a discussão para uma possível necessidade de suplementação.

A avaliação dos níveis e a provável suplementação de selênio, como farmacoterapia para pacientes criticamente doentes tem sido uma área interessante de pesquisa em cuidados intensivos. E, apesar dos resultados promissores, mais estudos são necessários para determinar a frequência das dosagens, a dose ideal e o tempo de administração, respeitando a individualidade bioquímica de cada paciente.

\section{CONCLUSÃO}

Aproximadamente $50 \%$ dos pacientes críticos foram admitidos na UTI com selênio abaixo dos valores de referência. À admissão e na evolução até o sétimo dia, os pacientes classificados de alto risco apresentaram a dosagem de selênio abaixo do valor de referência e inferior ao daqueles com risco moderado.

\section{REFERÊNCIAS}

1. Duntas LH, Benvenga S. Selenium: an element for life. Endocrine. 2014;48(3):756-75.

2. Kieliszek M, Błazejak S. Current knowledge on the importance of selenium in food for living organisms: a review. Molecules. 2016;21(5):609.

3. Mahmoodpoor A, Hamishehkar H, Shadvar K, Ostadi Z, Sanaie $\mathrm{S}$, Saghaleini $\mathrm{SH}$, et al. The effect of intravenous selenium on oxidative stress in critically ill patients with acute respiratory distress syndrome. Immunol Invest. 2019;48(2):147-59.

4. Lee WJ, Chen YL, Chu YW, Chien DS. Comparison of glutathione peroxidase-3 protein expression and enzyme bioactivity in normal subjects and patients with sepsis. Clin Chim Acta. 2019;489:177-82.

5. Manzanares W, Biestro A, Galusso F, Torre MH, Mañay N, Pittini $\mathrm{G}$, et al. Serum selenium and glutathione peroxidase-3 activity: biomarkers of systemic inflammation in the critically ill? Intensive Care Med. 2009;35(5):882-9.

6. Swart R, Schutte AE, van Rooyen JM, Mels CMC. Serum selenium levels, the selenoprotein glutathione peroxidase and vascular protection: the SABPA study. Food Res Int. 2017;104:69-76.

7. Hosnedlova B, Kepinska M, Skalickova S, Fernandez C, RuttkayNedecky B, Donald Malevu T, et al. A summary of new findings on the biological effects of selenium in selected animal species: a critical review. Int J Mol Sci. 2017;18(10):2209.

8. Mertens K, Lowes DA, Webster NR, Talib J, Hall L, Davies MJ, et al. Low zinc and selenium concentrations in sepsis are associated with oxidative damage and inflammation. Br J Anaesth. 2015;114(6):990-9.

9. McMillan DC. Systemic inflammation, nutritional status and survival in patients with cancer. Curr Opin Clin Nutr Metab Care. 2009;12(3):223-6.

10. Lima KVG, Maio R. Nutritional status, systemic inflammation and prognosis of patients with gastrointestinal cancer. Nutr Hosp. 2012;27(3):707-14.

11. Corrêa CR, Angeleli AYO, Camargo NR, Barbosa L, Burini RC. Comparação entre a relação PCR / albumina e o índice prognóstico inflamatório nutricional (IPIN). J Bras Patol Med Lab. 2002;38(3):183-90.

12. Anthony PS. Nutrition screening tools for hospitalized patients. Nutr Clin Pract. 2008;23(4):373-82. 
13. Lima JCC, Moreira A, Lima D, Correia LCL. Validação da medida de proteína C-reativa de alta sensibilidade (PCR-as) por quimioluminescência para estimativa de risco cardiovascular em indivíduos ambulatoriais: análise comparativa com nefelometria. J Bras Patol Med Lab. 2005;41(1):15-9.

14. Sakr Y, Reinhart K, Bloos F, Marx G, Russwurm S, Bauer M, et al. Time course and relationship between plasma selenium concentrations, systemic inflammatory response, sepsis, and multiorgan failure. Br J Anaesth. 2007;98(6):775-84.

15. Lew CCH, Yandell R, Fraser RJL, Chua AP, Chong MFF, Miller M. Association between malnutrition and clinical outcomes in the intensive care unit: a systematic review. JPEN J Parenter Enter Nutr. 2017;41(5):744-58.

16. Mueller C, Compher C, Ellen DM; American Society for Parenteral and Enteral Nutrition (A.S.P.E.N.) Board of Directors. A.S.P.E.N. clinical guidelines: nutrition screening, assessment, and intervention in adults. JPEN J Parenter Enter Nutr. 2011;35(1):16-24.

17. Gonzaga I, Martens A, Cozzolino S. Selênio. In: Cozzolino SMF, eds. Biodisponibilidade de nutrientes. $3^{\text {a }}$ ed. Barueri: Manole; 2009.

18. Heyland D, Muscedere J, Wischmeyer PE, Cook D, Jones G, Albert M, et al; Canadian Critical Care Trials Group. A randomized trial of glutamine and antioxidants in critically ill patients. N Engl J Med. 2013;368(16):1489-97.

19. Costa NA, Gut AL, Pimentel JA, Cozzolino SM, Azevedo PS, Fernandes AA, et al. Erythrocyte selenium concentration predicts intensive care unit and hospital mortality in patients with septic shock: a prospective observational study. Crit Care. 2014;18(3):R92.

20. McClave SA, Taylor BE, Martindale RG, Warren MM, Johnson DR, Braunschweig C, et al; Society of Critical Care Medicine; American Society for Parenteral and Enteral Nutrition. Guidelines for the provision and assessment of nutrition support therapy in the adult critically ill patient: Society of Critical Care Medicine (SCCM) and American Society for Parenteral and Enteral Nutrition (A.S.P.E.N.). JPEN J Parenter Enter Nutr. 2016;40(2):159-211.

21. Langlois PL, Hardy G, Manzanares W. Pharmaconutrition with intravenous selenium in intensive care: the end of an era? Nutrition. 2018;45:142-4.

22. Critical Care Nutrition. Canadian Clinical Practice Guidelines 2015 - Summary of revisions to the recommendations. Crit Care Nutr [Internet]. 2015;1:1-12.

23. Manzanares W, Langlois PL, Hardy G. Selenium pharmaconutrition in sepsis: to give or not to give? Is this still the question? Nutrition. 2013;29(11-12):1429-30.

24. Andrews PJ, Avenell A, Noble DW, Campbell MK, Croal BL, Simpson WG, et al; Scottish Intensive care Glutamine or seleNium Evaluative Trial Trials Group. Randomised trial of glutamine, selenium, or both, to supplement parenteral nutrition for critically ill patients. BMJ. 2011;342:d1542.

25. Singer P, Manzanares W, Berger MM. What's new in trace elements? Intensive Care Med. 2018;44(5):643-5.

Local de realização do estudo: Universitário Júlio Muller/ Universidade Federal de Mato Grosso, Programa de Mestrado Profissional, Cuiabá, MT, Brasil.

Conflito de interesse: Os autores declaram não haver.

Trabalho apresentado na modalidade Temas Livres no $21^{\circ}$ Fórum Paulista de Pesquisa em Nutrição Clínica e Experimental no Ganepão 2019: $8^{\circ}$ Congresso Brasileiro de Nutrição Integrada - CBNI e $4^{\circ}$ Congresso Brasileiro de Pré, Pró e Simbióticos PreProSim, de 11 a 14 de junho de 2019, no Centro de Convenções Rebouças, São Paulo, SP, Brasil. 